\title{
La reinserción social post penitenciaria: un reto a la justicia ecuatoriana
}

\author{
Fecha de recepción : 2019-09-20 • Fecha de aceptación: 2020-08-11 • Fecha de publicación: 2021-10-01
}

Osvaldo P. Brito Febles'

Universidad Metropolitana del Ecuador (UMET)

obrito@umet.edu.ec

https://orcid.org/0000-0001-7803-0080

Byron Ramiro Alcocer Castillo²

Maldonado y asociados. Abogados S.A, Ecuador

balcoccer@gmail.com

https://orcid.org/0000-0003-2672-2215

\section{Resumen}

Los seres humanos pueden reflejar sus bondades y miserias durante su vida, unas de esas miserias adquiridas por naturaleza o por aprendizaje social, en todo caso destructivas, pueden actuar como hilo conductor al delito. Como defensa contra el delito se crearon las penas y dentro de ellas, la prisión, cuya finalidad es que el ciudadano asuma una serie de valores básicos para la convivencia social en un régimen de democracia y justicia donde se respetan los derechos subjetivos y humanos. Esto significa que la pena debe estar fundamentada en políticas claves para la rehabilitación del individuo y su reinserción normal a la sociedad, lo que requiere un Estado que se preocupe no sólo por fijar las políticas, sino aplicarlas, hacerles seguimiento y evaluarlas para dejarlas, cambiarlas o eliminarlas. La presente investigación tiene como propósito analizar si es efectiva la reinserción social del penado en Ecuador, lo que se justifica por las exigencias constitucionales del Estado ecuatoriano. Para dar cumplimiento al objetivo del estudio se aplicó una metodología de carácter cuantitativa y cualitativa (mixta) en la que se unen estudios doctrinales y legales a la aplicación de una encuesta a los internos de la cárcel de Cotopaxi. 
Palabras clave: reinserción, rehabilitación, post penitenciaría, penado, Ecuador.

\begin{abstract}
Human beings can reflect their kindness and miseries in their lives, some of those miseries acquired by nature or by social learning, in any case destructive, can act as a common thread to crime. As a defense against crime, penalties were created and within them, prison, which aims to encourage the citizen to assume a series of basic values for social coexistence in a regime of democracy and justice where subjective rights are respected and humans. This means that the sentence must be based on key policies for the rehabilitation of the individual and their normal reintegration into society, which requires a State that is concerned not only with setting policies, but also applying, monitoring and evaluating them in order to leave them, change or delete them. The purpose of this research is to analyze if the reintegration of the prisoner in Ecuador is effective, which is justified by the constitutional requirements of the Ecuadorian State. To fulfill the objective of the study, a quantitative and qualitative (mixed) methodology is applied, in which doctrinal and legal studies are combined with the application of a survey to the inmates of the Cotopaxi prison.
\end{abstract}

Keywords: reintegration, rehabilitation, post penitentiary, convicted, Ecuador. 


\section{Introducción}

Una persona goza de atributos personales, entre ellos: la vida, dignidad, libertad, salud, la integridad, patrimonio, etcétera. Estos se denominan bienes jurídicos, porque son tutelados por el derecho, cuando estos son afectados el Estado aplica una pena a los infractores, este tiene como función garantizar la seguridad, por ello debe sancionar a quien infrinja la ley penal, lo que puede conducir al encierro del culpable. La reclusión, muchas veces se acompaña de maltratos y carencias que vuelven al individuo más violento que cuando ingresó, afectando a los otros privados de libertad. Por eso, la Fundación Regional de Asesoría en Derechos Humanos (INREDH), manifiesta que "encerrar a una persona, someterle a tortura y tratos inhumanos no son formas de reinsertar o rehabilitarla" (Ecuador Chequea, 2018).

Por tal motivo, el sistema penitenciario debe planificar y ejecutar actividades relacionadas con el estudio, trabajo, salud, alimentación y el trato digno al recluso, bajo el respeto de los Derechos Humanos. El presente artículo trata la problemática de reinserción social post penitenciaria en Ecuador mediante un estudio teórico y jurídico.

El estudio se justifica debido a las exigencias que sobre el particular hacen los instrumentos internacionales relacionados con los Derechos Humanos y especialmente, la Constitución de la República del Ecuador. Metodológicamente es una investigación mixta donde se utiliza la indagación documental y de campo. Los métodos usados en el desarrollo de la investigación fueron el de análisis, síntesis, deductivo, inductivo y crítico. En cuanto al trabajo de campo se utilizó una muestra de treinta (30) ex reclusos del Centro de Reclusión Social Cotopaxi, a los que se le aplicó una encuesta para conocer los programas de rehabilitación social de los que se beneficiaron.

Este artículo analiza hasta qué punto los reclusos sufren violaciones a sus Derechos Humanos y si ésta los regenera o deteriora más su conducta, lo que llevaría a tomar posición en torno a la pertinencia social de dichos centros de reclusión. Se realiza un examen de los fundamentos doctrinales y jurídicos relacionados con la reinserción social del exrecluso y se exponen los resultados.

\section{La pena}

Para comenzar, es fundamental partir de la doctrina llamada clásica acerca de la pena, la que se define desde el punto de vista clásico como: "la pena tiene un carácter de retribución moral y, como tal, presupone que ha de sufrirla un sujeto moralmente imputable" (Soler, 1992). Sobre ella se indica que es "uno de los instrumentos más característicos con que cuenta el Estado para imponer sus normas jurídicas, y su función depende de la que se asigne al Estado" (Mir Puig, 2002,p.3). La sanción se perfila como un medio de control de la sociedad para lograr la paz y la seguridad.

La pena debe imponerse desde la legalidad y la proporcionalidad. Estas se aplican mediante la privación de libertad para delitos graves y fórmulas alternativas a esta, como multas o privación de derechos, para delitos menores o faltas. Al Estado se atribuye la imposición de penas como medio 
de control social legítimo. La Organización de Naciones Unidas (2007) sostiene que la finalidad y justificación de las penas son proteger a la sociedad contra el crimen y solo es posible alcanzarlo aprovechando el período de reclusión para lograr que el infractor al ser liberado respete la ley y sea capaz de proveer sus necesidades.

La ONU (2007) indica que para lograr este propósito el régimen penitenciario debe tener en cuenta las necesidades del tratamiento individual que debe brindársele a cada reo y con base a ello, poner a su disposición los medios curativos, educativos, espirituales y de otra naturaleza, además de otras formas de asistencia.

\subsection{La finalidad de la pena en Ecuador y su clasificación}

La Constitución de la República (2008) establece en el Art. 11.9 que el Estado debe respetar y hacer respetar los derechos reconocidos constitucionalmente. Igualmente, el, sus delegatarios, concesionarios y cualquier persona que ejerza una potestad pública, está obligada a reparar las violaciones a los derechos de las personas por la falta o deficiencia en la prestación de los servicios públicos, o por cualquier acción u omisión de sus funcionarios y empleados públicos en el desempeño de sus funciones. El Estado es responsable de cualquier detención arbitraria, error judicial, retardo injustificado o inadecuada administración de justicia, vulneración del derecho a la tutela judicial efectiva, y por las violaciones de los principios y reglas del debido proceso. Por ello, los funcionarios deben respetar los tipos de penas previstos en la norma, su aplicación y finalidad.

El artículo 51 del texto constitucional (2008), reconoce que las personas privadas de la libertad deben recibir un trato digno y ejercitar sus derechos a la salud, educación, trabajo, alimentación, etcétera. Se contempla, además, la atención especial hacia los derechos de las mujeres en estado de gravidez, los niños, niñas y adolescentes infractores, adultos mayores y personas con discapacidad.

A su vez, el artículo 66 la Constitución (2008) proscribe la pena de muerte, asegurando la inviolabilidad de la vida, reconoce la dignidad de esta bajo el disfrute y ejercicio de sus derechos que permita satisfacer sus necesidades. Los privados de libertad deben gozar de los mismos derechos que las personas restantes, sino se vulneran sus Derechos Humanos.

Así mismo, la Constitución garantiza a todos, sin discriminación, el derecho a la integridad física, psíquica, moral y sexual. Se prohíbe la tortura, la desaparición forzada, los tratos y penas crueles, inhumanos o degradantes, el trabajo forzoso, la esclavitud, la explotación y la servidumbre.

En el artículo 76 de la norma suprema (2008) se regulan las garantías básicas del debido proceso, entre ellas, el numeral 3 preceptúa que ninguna persona puede ser juzgada ni sancionado por una acción u omisión, que, al momento de ejecutarla, no esté tipificado en la ley como delito; prevé el principio de indubio pro reo y el principio de proporcionalidad de la pena en relación con la infracción cometida. 
La Constitución (2008) en el artículo 77 dispone las garantías básicas para las personas privadas de libertad, entre ellas, que la libertad es la regla y la privación de libertad es la excepción, aplicándose sólo para garantizar la comparecencia del imputado al proceso, el derecho de la víctima del delito a una justicia oportuna y sin dilaciones para asegurar el cumplimiento de la pena y que la privación de la libertad para los adolescentes se empleara como último recurso, por un periodo mínimo y en establecimientos diferentes a los de personas adultas.

En ese sentido, la norma constitucional (2008) establece que se exceptúan en todos los casos los delitos flagrantes, en cuyo caso, la persona no puede estar detenida sin formula de juicio por más de veinticuatro horas, tampoco las personas privadas de libertad pueden incomunicarse y que la prisión preventiva no podrá exceder de seis meses en las causas por delitos sancionados con prisión, ni de un año en los casos de delitos sancionados con reclusión.

Igualmente, el artículo 77 de la Constitución (2008) prevé que los jueces aplicarán las medidas cautelares alternativas a la privación de libertad contempladas en la ley y las sanciones alternativas de acuerdo con los casos, plazos, condiciones y requisitos establecidos y que las personas declaradas culpables y condenadas a la pena de privación de libertad, permanecerán en centros de rehabilitación social y que ninguna persona sancionada por delitos comunes, cumplirá la pena fuera de ellos, excepto los casos de penas alternativas y de libertad condicionada, de conformidad con la ley. En el caso de adolescentes infractores, se regula un tratamiento diferente basado en medidas socioeducativas proporcionales a la infracción cometida.

Lo antes expuesto refleja que el Estado es el único que, mediante sus instituciones, puede ejercer la coerción y aplicar las sanciones de acuerdo con la normativa. Como una garantía para los infractores, la Constitución (2008) regula que, al resolverse la impugnación de una sanción no se podrá empeorar la situación del recurrente.

En consonancia con la norma constitucional, el Código Orgánico Integral Penal define la pena en el artículo 51 como una "restricción a la libertad y a los derechos de las personas, como consecuencia jurídica de sus acciones u omisiones punibles. Se basa en una disposición legal e impuesta por una sentencia condenatoria ejecutoriada" (Código Orgánico Integral Penal, 2014, p.14).

Por su parte, el artículo 52 el COIP (2014) estipula que la finalidad de la sanción es la prevención general para la comisión de delitos y el desarrollo paulatino de los derechos y capacidades de la persona condenada y busca la reparación del derecho de la víctima. A su vez, que la sanción no implica el aislamiento y la neutralización de los infractores, además, que a los reos debe dárseles la oportunidad, desde el encierro, de recibir educación y desarrollar trabajos u oficios que los preparen para su reinserción social.

EI COIP (2014) regula en el 53 la legalidad de la pena y prohíbe imponer sanciones indefinidas y más severas que las determinadas en los delitos, esto significa que el juez no puede imponer una pena fuera de la ley. Ello se relaciona con el Derecho Penal Mínimo, que postula que la sanción debe reducirse hasta abolirla y que sólo se justifica para prevenir el delito. 
La individualización de la pena está regulada en el artículo 54 de la norma penal (2014), por lo que el juez debe imponerla tomando en cuenta las particularidades de cada persona, definiendo el grado de participación y las circunstancias del hecho. Los artículos 55, 56 y 57 del COIP prevén la agravación de las penas, ya sea por acumulación, o por reincidencia. La acumulación de penas privativas de libertad es por el máximo de cuarenta años y las penas de multas se acumulan hasta el doble de la máxima impuesta. En cuanto a la clasificación de las penas, el COIP las clasifica en sus artículos 58 al 71 en penas principales o accesorias, las que, a su vez, pueden ser privativas, no privativas de libertad y restrictivas de los derechos de propiedad.

\subsection{La administración de las penas en el contexto de los Derechos Humanos}

Luego de la culminación de la Segunda Guerra Mundial se suscribe la Declaración Universal de los Derechos Humanos a raíz de que se han producido numerosas reglas y normas que regulan la vida en los centros penitenciarios, tales como: las Reglas Mínimas de las Naciones Unidas para el Tratamiento de los Reclusos.

Estas reglas (2007) evidencian como principio fundamental su aplicación imparcial, sin discriminación de trato fundadas en la raza, color, sexo, religión o de cualquier otra clase. Igualmente, que en todo sitio donde existan detenidos, se debe existir un registro diario que indique información de identidad, sobre la detención y la autoridad que la ordenó. Indica que los reos deben separarse por categorías, según su sexo y edad, antecedentes criminales, los motivos de detención y el trato a aplicarles.

Además, que en la noche los reclusos estarán sometidos a una vigilancia regular, contarán con una superficie mínima, condiciones higiénicas, luz, ventilación y calefacción de ser necesaria. En el local donde vivan o trabajen, debe tener amplios ventanales, que permita leer y trabajar con luz natural. Las instalaciones sanitarias deberán ser adecuadas e higiénicas para que puedan satisfacer sus necesidades. Se les debe proveer de agua y alimentos, así como de los artículos de aseo indispensables para su salud.

En los establecimientos para mujeres deben existir instalaciones especiales para las reclusas embarazadas, madres y las convalecientes. Hasta donde sea posible, se debe asegurar que el parto ocurra en un hospital civil, si el niño nace en el establecimiento ello no debe constar en su partida de nacimiento.

En relación con la disciplina, un recluso solo se podrá sancionar de acuerdo con las normativas vigentes, sin que pueda serlo nunca dos veces por la misma infracción. Se prohíben las penas corporales, encierro en celda oscura, así como tratos crueles, inhumanos o degradantes y el empleo de medios de coerción como esposas, cadenas, grillos y camisas de fuerza. Las sanciones no deben ser prolongadas más de lo necesario. A reserva de las medidas de separación justificadas o del mantenimiento de la disciplina, las que no deben agravar los sufrimientos de los reclusos.

La ONU (2007) considera que la política de los establecimientos penitenciarios debe tratar de disminuir las diferencias entre la estadía en prisión y la vida libre. Al igual que, antes del término 
de la ejecución de un castigo o medida, se deben aplicar las medidas necesarias para asegurar al recluso un regreso progresivo a la vida en sociedad. Este objetivo puede alcanzarse con una política inicial para la prelibertad, que inicia dentro del establecimiento o en otra institución adecuada o mediante una liberación eventual.

En este mismo sentido, durante el proceso no se debe excluir a los reclusos de la colectividad, por ello se debe acudir a la colaboración comunitaria en la tarea de la recuperación social de los reos. A estos fines, se debe contar con el trabajo y apoyo de trabajadores sociales, de los organismos que puedan ser de utilidad en el proceso de reinserción social y gestionarse en lo posible, la recuperación de los derechos de la seguridad social y otras mejoras sociales.

El deber de la sociedad no termina con la liberación del recluso, sino que una vez puesto en libertad se debe trabajar en la ayuda post penitenciaria que coadyuve a la disminución de los prejuicios hacia él y le permitan readaptarse a la vida cotidiana. Con respecto al trabajo carcelario, se dispone que debe enfocarse en mejorar su aptitud y actitud física y mental, para que en un futuro la reinserción social no resulte drástica (ONU, 2007).

Así mismo, se dará a los reclusos una formación profesional en algún oficio que los prepare para las condiciones normales del trabajo libre. En caso de necesitarlo, se deben alfabetizar. Igualmente se debe estimular el mantenimiento y establecimiento de relaciones sociales, también los servicios y entidades, interesados en la reinserción social del ex recluso, deben suministrarles los documentos y certificados de identidad y los medios para que lleguen a su destino y puedan subsistir el período posterior a su liberación.

Corresponde decir que acerca de los reclusos alienados y enfermos mentales, la ONU (2007) mantiene que deben ser recluidos en entidades para enfermos y deben tomarse las previsiones para que, al ser liberados, continúen su tratamiento. En el caso las personas detenidas o en prisión preventiva, gozarán de la presunción de inocencia y así debe ser tratados.

Por otra parte, están las reglas mínimas denominadas Reglas Nelson Mandela (2015), cuyo objeto es enunciar los elementos adecuados e idóneos para tratar a los reclusos y la administración penitenciaria. En ellas se prevé que los reclusos deben ser respetados y tratados acordes a la dignidad humana, que no deben ser sometidos a tortura ni a otros tratos o penas crueles, inhumanos o degradantes. Se debe velar por la seguridad de los reclusos, el personal, los proveedores de servicios, visitantes y que no exista discriminación alguna en dichos establecimientos. Así mismo, ratifica los objetivos de las penas y medidas privativas de libertad encaminados a prevenir el delito y reducir la reincidencia. Por ello, las administraciones penitenciarias deben ofrecer educación, formación profesional, trabajo y otras formas de asistencias apropiadas.

\section{La cárcel: una mirada crítica}

El asunto del propósito del encarcelamiento y su eficacia resulta polémico y existen tres criterios predominantes al respecto: Es un medio para castigar al delincuente que con su conducta ha 
afectado la sociedad. Es una forma de disuadir al infractor para que no reincida y alertar a quienes puedan mostrar proclividad al delito y que la cárcel tiene un fin reformatorio y rehabilitatorio.

Por otra parte, la reclusión genera gastos, por lo que el Estado debe planificar presupuestos para pagar personal, alimentación, vestuario, instalaciones, entre otros, lo que se podría invertir en otros rubros sociales. Este es uno de los motivos por los que la privación de libertad no es la solución más eficaz ante el delito.

El papel fundamental del sistema penitenciario es la rehabilitación y la preparación para la post penitenciaria. La reinserción social está referida a la acción de regresar el infractor al grupo social que afectó con el delito, pero debe prepararse para ello. Esta rehabilitación es parte del campo del trabajo social, es un proceso de orientación profesional especializada, tendiente a que la persona tome consciencia de sí mismo, de su rol como ser humano.

Lo planteado refleja que la reinserción social requiere un proceso sistemático de acciones que comienzan desde el ingreso de la persona al centro de reclusión, continua durante el cumplimiento de la sanción y finaliza con la libertad, pasando al período post penitenciario.

Un aspecto fundamental para la reinserción es el trabajo en el centro penitenciario, sin este se multiplica la pobreza de los recluidos y puede generar violencia y delincuencia intrapenitenciaria. Esta actividad ayuda la adquisición de hábitos laborales, evita el deterioro físico y psicológico y les posibilita un ingreso económico. El trabajo es una herramienta eficaz y rehabilitadora.

Por otro lado, cuando el reo llega a la etapa post penitenciaria, el Estado debe contribuir al desarrollo de la persona liberada, evitar su discriminación por parte de la sociedad, coadyuvar a su inserción al empleo remunerado. De necesitarlo acceda a asistencia médica, y a que cuente con apoyo familiar y social.

\subsection{Las personas privadas de libertad en Ecuador}

En el año 2018, según el Ministerio de Justicia Derechos Humanos y Cultos (2018), existían en el Ecuador 55 Centros de Rehabilitación Social. Para finales de 2017 existían 29.231 privados de libertad, y la capacidad de sus centros de reclusión es de 17.261, existiendo una sobrepoblación de 11.970 reclusos, que representa un $41 \%$ de hacinamiento. Ello ocasiona problemas dentro de un centro de reclusión, como: violencia, materializada en violaciones, robos, homicidios, insalubridad, vulneración de Derechos Humanos, lo que incide negativamente en su rehabilitación.

En este contexto, el Diario El Comercio (2018) afirma, que, 11 presos murieron en 8 cárceles en el año 2018, lo que significa un alto índice de homicidios en ellas y muestra la presencia del crimen organizado que amedrenta, mata y lesiona a reos, este ambiente no favorece la rehabilitación. Lo expuesto muestra que lo establecido en la Constitución y la ley queda en una mera formalidad jurídica esto implica que debe haber una política pública acertada para erradicar estos actos de violencia en las prisiones. 
Como se ha dicho, el respeto a la integridad física del privado de libertad es una garantía constitucional. Por ello se recomienda que ante cualquier violación a esta garantía se debe dejar constancia pericial y solicitar a la Fiscalía la práctica de un reconocimiento médico legal o psicológico para asegurar la prueba que sustentará la acción penal respectiva.

Con respecto a los derechos, tanto la norma constitucional como los instrumentos internacionales de Derechos Humanos le reconocen al recluso los relacionados con el trabajo, la educación, la cultura, recreación, salud y buena alimentación. Igualmente, para evitar la violencia interna, el COIP (2014) en el artículo 275 tipifica el hecho de ingresar artículos prohibidos y lo sanciona con pena privativa de libertad de uno a tres años y en el artículo 718 prohíbe el ingreso de armas, bebidas alcohólicas, sustancias estupefacientes o psicotrópicas, teléfonos o equipos de comunicación o cualquier instrumento que atenta contra la seguridad y paz de la prisión.

Cabe agregar que los jueces de garantías penitenciarias deben visitar mensualmente los centros carcelarios de su cantón para supervisar el cumplimiento de este régimen penitenciario, el respeto de las garantías constitucionales y legales, intercambiar con los internos y tomar decisiones.

Acerca de la rehabilitación post penitenciaria en el país, debe decirse que se ha realizado un esfuerzo para lograrla. Para ello se reformó el Sistema de Rehabilitación Social mediante el Modelo de Gestión Penitenciaria que incluye la remodelación, nueva infraestructura y construcción de nuevos centros con el objetivo de disminuir el hacinamiento carcelario.

Se procedió a la creación de un Centro de Formación de Agentes Penitenciarios a nivel técnico. Se suscribieron acuerdos Ministeriales para garantizar el derecho a la educación para adolescentes y adultos privados de la libertad. Se logró el trabajo remunerado para los reos, se desarrollan operativos de control en las celdas en búsqueda de drogas, armas blancas, celulares, etcétera, para evitar la violencia y se aplica una política de aceleración de juicios para los procesados.

De lo expuesto, se puede desprender que, en Ecuador, a pesar de las estrategias que se han seguido, no se cumple con el principio de la rehabilitación de los exreclusos y las bases teóricas confirman, que, existe un sistema de penas que contemplan la prisión y que, dentro de ella, no se cumplen las exigencias legales para la protección de los reclusos, ni para asegurar su rehabilitación.

\section{Metodología}

Esta investigación usó un método mixto, se utilizó la investigación teórica para analizar los fundamentos doctrinales y jurídicos acerca de la reinserción social del exrecluso. Se empleó la investigación cuantitativa e igualmente se utilizó el de análisis, empleado para desglosar el tema de la reinserción social post penitenciaria en Ecuador.

Otros de los métodos fue el de síntesis, que permitió reconstruir el material analizado e interpretarlo para llegar a conclusiones certeras. Se utilizó el método deductivo para estructurar los contenidos doctrinales y jurídicos, organizados desde lo general a lo particular y los métodos inductivo y crítico para realizar cuestionamientos a los elementos estudiados. 
También se empleó la técnica del cuestionario mediante la aplicación de una encuesta para colectar y registrar datos sobre los elementos penitenciarios y post penitenciarios que inciden en la rehabilitación. Al aplicar el instrumento se tuvo en cuenta una población de 30 ex reclusos de la cárcel de Cotopaxi, que egresaron entre 2015 y 2017 y radican en el sur de Quito.

\section{Resultados}

El instrumento aplicado arrojó los siguientes resultados:

Tabla 1.

Resultados pregunta 1: ¿Cuándo lo apresaron lo golpearon?

\begin{tabular}{|l|l|l|}
\hline Alternativa & $\mathrm{F}$ & Porcentaje (\%) \\
\hline $\mathrm{Si}$ & 21 & $\mathbf{7 0}$ \\
\hline No & 09 & 30 \\
\hline Totales & $\mathbf{3 0}$ & $\mathbf{1 0 0 \%}$ \\
\hline
\end{tabular}

Fuente: elaboración propia

En la Tabla 1 el $70 \%$ de la muestra afirma que fue golpeada al ser apresado, lo que resulta contraria al respeto a los Derechos Humanos. Atendiendo a que existen instrumentos internacionales que obligan al personal de las instituciones penitenciarias a toda persona detenida o que se encuentre en prisión debe tratarse con respeto y dignidad.

Tabla 2.

Resultados pregunta 2: ¿Cuándo lo detuvieron, le permitieron de inmediato que llamara a un abogado?

\begin{tabular}{|l|l|l|}
\hline Alternativa & F & Porcentaje (\%) \\
\hline $\mathrm{Si}$ & 3 & 10 \\
\hline No & 27 & 90 \\
\hline Totales & $\mathbf{3 0}$ & $\mathbf{1 0 0 \%}$ \\
\hline
\end{tabular}

Fuente: elaboración propia

En la Tabla 2 la mayoría de los exreclusos (90\%) afirman que cuándo lo detuvieron, no le permitieron de inmediato llamar a un abogado, esto resulta contrario a las garantías del debido proceso.

Tabla 3.

Resultados pregunta 3: ¿En el tiempo que estuvo preso, le dieron la oportunidad de estudiar?

\begin{tabular}{|l|l|l|}
\hline Alternativa & $\mathrm{F}$ & Porcentaje (\%) \\
\hline $\mathrm{Si}$ & 4 & 13 \\
\hline No & 26 & 87 \\
\hline Totales & $\mathbf{3 0}$ & $\mathbf{1 0 0} \%$ \\
\hline
\end{tabular}

Fuente: elaboración propia 
Un $87 \%$ de la muestra indica que no le dieron la oportunidad de estudiar, lo que contradice las normas internacionales y el ordenamiento jurídico interno sobre las oportunidades que debe darse a los reclusos en esta área (Tabla 3).

Tabla 4.

Resultados pregunta 4: ¿En el tiempo que estuvo preso, le dieron la oportunidad de trabajar?

\begin{tabular}{|l|l|l|}
\hline Alternativa & F & Porcentaje (\%) \\
\hline $\mathrm{Si}$ & 2 & 7 \\
\hline No & 27 & 90 \\
\hline Totales & $\mathbf{3 0}$ & $\mathbf{1 0 0} \%$ \\
\hline
\end{tabular}

Fuente: elaboración propia

Como se evidencia en la Tabla 4 el $90 \%$ de la muestra afirma que en el tiempo que estuvo preso no le dieron la oportunidad de trabajar, lo que viola las Normas Internacionales de Derechos Humanos para Funcionarios de Instituciones Penitenciarias de la ONU (2005), así como la norma constitucional vigente. La cual plantea que los reclusos tendrán la obligación de trabajar remuneradamente, para con esto contribuir a aumentar su capacidad para ganarse la vida después de su liberación.

Tabla 5.

Resultados pregunta 5: ¿Cómo era la comida en el centro de reclusión mientras estuvo detenido?

\begin{tabular}{|l|l|l|}
\hline Alternativa & F & Porcentaje (\%) \\
\hline Buena & 0 & 0 \\
\hline Regular & 13 & 32 \\
\hline Mala & 17 & 68 \\
\hline Totales & $\mathbf{3 0}$ & $\mathbf{1 0 0 \%}$ \\
\hline
\end{tabular}

Fuente: elaboración propia

Cuando se les consultó ¿Cómo era la comida en el centro de reclusión mientras estuvo detenido? (Figura 5) la mayoría de la muestra (68\%) indicó que la comida era mala y el $32 \%$ que era regular, ello vulnera los Derechos Humanos, la Constitución y las disposiciones de esta materia. Al respecto se exige por la ONU (2005) que todo recluso debe recibir en su horario, alimentación de buena calidad y en cantidad suficiente.

Tabla 6.

Resultados pregunta 6: ¿Cuándo se enfermaba, lo atendía inmediatamente el médico?

\begin{tabular}{|l|l|l|}
\hline Alternativa & F & Porcentaje (\%) \\
\hline $\mathrm{Si}$ & 3 & 10 \\
\hline No & 27 & 90 \\
\hline Totales & $\mathbf{3 0}$ & $\mathbf{1 0 0 \%}$ \\
\hline
\end{tabular}

Fuente: elaboración propia 
En la Figura 6 se puede ver que el $90 \%$ de la muestra señala que no existe atención médica inmediata, ello afecta el derecho a la salud y contraviene los instrumentos internacionales y normas internas acerca de los Derechos Humanos teniendo en cuenta que, tanto los reclusos, como los detenidos, tienen derecho a la salud física y mental, acceso a los servicios de salud y el médico del centro penitenciario juega un rol importante en la satisfacción de este derecho.

Tabla 7.

Resultados pregunta 7: ¿Había agua suficiente en el centro penitenciario para beber, bañarse y mantener limpia la celda?

\begin{tabular}{|l|l|l|}
\hline Alternativa & F & Porcentaje (\%) \\
\hline $\mathrm{Si}$ & 6 & 20 \\
\hline No & 24 & 80 \\
\hline Totales & $\mathbf{3 0}$ & $\mathbf{1 0 0 \%}$ \\
\hline
\end{tabular}

Fuente: elaboración propia

Mientras que el $80 \%$ de la muestra afirmó que no disponían de agua suficiente en el centro penitenciario para bañarse y mantener limpia la celda (Figura 7), esta dificultad es violatoria de las Normas Internacionales de Derechos Humanos para Funcionarios de Instituciones Penitenciarias de la ONU (2005), porque el derecho al agua es fundamental. Ello refleja que no existe satisfacción de las necesidades de salud e higiene, ni el médico y la administración del centro cumple con las inspecciones periódicas para evaluar la higiene y servicios básicos del centro.

Tabla 8.

Resultados pregunta 8: ¿Recibía buen trato del personal que atiende el centro penitenciario?

\begin{tabular}{|l|l|l|}
\hline Alternativa & F & Porcentaje (\%) \\
\hline $\mathrm{Si}$ & 7 & 23 \\
\hline No & 23 & 77 \\
\hline Totales & $\mathbf{3 0}$ & $\mathbf{1 0 0 \%}$ \\
\hline
\end{tabular}

Fuente: elaboración propia

Como se refleja en la Figura 8 , la mayoría de la muestra (77\%) expreso no hacer recibido buen trato del personal que atiende el centro penitenciario, esto es contrario a las Normas Internacionales de Derechos Humanos para Funcionarios de Instituciones Penitenciarias de la ONU (2005), puesto que toda persona sometida a detención o prisión debe tratarse humanamente y respetar su dignidad humana. Se definen por la ONU (2005) como malos tratos aquellos que impliquen penas crueles, inhumanas o degradantes. 
Tabla 9.

Resultados pregunta 9: ¿Con cuántas personas estaba en su celda?

\begin{tabular}{|l|l|l|}
\hline Alternativa & $\mathbf{F}$ & Porcentaje (\%) \\
\hline Con 5 o 6 & 18 & 60 \\
\hline Con 3 o 4 & 7 & 23 \\
\hline Más de 6 & 5 & 17 \\
\hline Totales & $\mathbf{3 0}$ & $\mathbf{1 0 0 \%}$ \\
\hline
\end{tabular}

Fuente: elaboración propia

A la pregunta de ¿Con cuántas personas estaba en su celda? (Figura 9) el $60 \%$ de la muestra informó que compartían la celda con 5 o 6 personas más. Al respecto las normativas internacionales de la materia (2005) establecen que los reclusos que deban compartir dormitorios deberán ser seleccionados y vigilados durante la noche. Ello ilustra la situación de hacinamiento en que están los reos y la necesidad de resolver dicho problema para respetar y cumplir con las disposiciones en materia de Derechos Humanos y sistema penitenciario.

Tabla 10.

Resultados pregunta 10: ¿Cómo ha sido tu experiencia en el centro de rehabilitación?

\begin{tabular}{|l|l|l|}
\hline Alternativa & F & Porcentaje (\%) \\
\hline Muy Buena & 1 & 3 \\
\hline Buena & 0 & 0 \\
\hline Regular & 6 & 20 \\
\hline Mala & 23 & 77 \\
\hline Totales & $\mathbf{3 0}$ & $\mathbf{1 0 0 \%}$ \\
\hline
\end{tabular}

Fuente: elaboración propia

El 97\% de los exreclusos indicaron que su experiencia en el centro de rehabilitación fue mala $(77 \%)$ o regular $(20 \%)$, ello refleja las malas condiciones existentes en los centros penitenciarios, la violación de Derechos Humanos que sufren, lo que es contrario a las normas y en consecuencia, no contribuye a la rehabilitación del ex recluso (Figura 10). 
Tabla 11.

Resultados pregunta 11: ¿Qué actividades aprendiste en el centro de rehabilitaciones?

\begin{tabular}{|l|l|l|}
\hline Alternativa & F & Porcentaje (\%) \\
\hline Vicios & 17 & 57 \\
\hline Nuevas formas de delinquir & 3 & 10 \\
\hline Oficios & 2 & 7 \\
\hline Nuevos deportes & 7 & 23 \\
\hline Todas las anteriores & 1 & 3 \\
\hline Totales & 30 & $100 \%$ \\
\hline
\end{tabular}

Fuente: elaboración propia

Y como pregunta final se hizo ¿qué actividades aprendiste en el centro de rehabilitaciones? (Figura 11) la mayor parte de la muestra, específicamente un $67 \%$, sostiene que lo aprendido fundamentalmente en el centro de rehabilitación fueron vicios y nuevas formas de delinquir, ello significa, que la cárcel no sirvió para rehabilitarlos. Esto obliga a cambiar la percepción con respecto a las sanciones y expone la necesidad de trabajar integralmente mediante acciones y políticas públicas para perfeccionar el sistema penitenciario ecuatoriano en el orden infraestructural y subjetivo para lograr la rehabilitación, ya que de la manera que actualmente se está desarrollando, vulnera los Derechos Humanos y a los fines de la pena.

\section{Conclusiones}

El individuo que delinque está sujeto a una pena, cuya finalidad es la prevención general para la comisión de delitos y el desarrollo progresivo de los derechos y capacidades de la persona con condena, así como la reparación del derecho de la víctima. En Ecuador las penas y su fin están contempladas en el COIP.

La rehabilitación del recluso implica habilitarlo para vivir nuevamente en sociedad, reinsertarlo en mejores condiciones que las que tenía antes de ser penado. Mediante la investigación se precisó que la rehabilitación es un proceso sistemático de acciones que conlleva tres etapas en las que ninguna excluye a la otra. La primera al ingresar el infractor al centro de reclusión; la segunda, se da durante el cumplimiento de la condena y la tercera cuando el ex condenado recobra su libertad y pasa al período post penitenciario. Por lo que las autoridades judiciales y penitenciarias deben cumplir las instrucciones previstas en normas internacionales para el cumplimiento de cada etapa para lograr la rehabilitación y la reinserción del excluso en la sociedad.

Los datos obtenidos de la aplicación del cuestionario indican, que, en Ecuador no es posible la rehabilitación del exrecluso porque no se cumple con la finalidad de la pena, lo que resulta contrario a la Constitución y a las normas provenientes de organismos internacionales de Derechos Humanos, además no se cumplen las etapas del proceso rehabilitatorio.

En Ecuador existe una vulneración de las normas previstas por la Organización de Naciones 
Unidas (ONU) y la norma constitucional acerca de los derechos de los penados. El trabajo de campo evidencia que los reclusos son maltratados durante el periodo de cumplimiento de la pena, constituyendo esto una limitante para su rehabilitación y su consecuente reinserción social. 


\section{Referencias}

Congreso de las Naciones Unidas sobre la Prevención del Delito y Tratamiento del Delincuente. (2015). Las Reglas Mínimas de las Naciones Unidas para el tratamiento de los reclusos (Reglas Nelson Mandela). https://parlamento.gub.uy/sites/default/files/DocumentosCPP/Reglas\%20Nelson\%20Mandela.pdf

Ecuador Chequea. (2018). El hacinamiento se ha reducido en las cárceles. http://www.ecuadorchequea. com/2018/05/28/hacinamiento-carceles-ecuador-gobierno-leninmoreno/

Ecuador, Asamblea Constituyente. (2008). Constitución de la República de El Ecuador. Quito: Registro Oficial $\mathrm{N}^{\circ} 449$ del lunes 20 de Octubre de 2008.

Ecuador, Asamblea Nacional. (2014). Código Orgánico Integral Penal. Quito: Registro Oficial Suplemento 180 de 10 de feb. 2014.

Ecuador, Asamblea Nacional. (2014, p.14). Código Orgánico Integral Penal. Quito: Registro Oficial Suplemento 180 de 10 de feb. 2014.

Ecuador, Ministerio de Justicia Derechos Humanos y Cultos. (2018) https://issuu.com/comisionjusticia/docs/ ppt final asamblea ministra de just

Mir Puig, S. (2002,p.3). Función de la pena y Teoría del Delito. Espasa Calpe: España.

Oficina del Alto Comisionado de las Naciones Unidas para los Derechos Humanos. (2005). Los Derechos Humanos y las Prisiones, Guía para el instructor en Derechos Humanos para funcionarios de prisiones. Ginebra: ONU. https://www.ohchr.org/Documents/Publications/training11Add2sp.pdf

Organización de Naciones Unidas. (2007). Recopilación de Reglas y Normas de las Naciones Unidas en la esfera de la Prevención del delito y la justicia penal. Viena: ONU. https://www.unodc.org/pdf/criminal justice/ Compendium UN Standards and Norms CP and CJ Spanish.pdf

Soler, S. (1992). Derecho Penal Argentino Tomo II. Buenos Aires: tea. http://www.academia.edu/28896423/Derecho Penal Argentino Sebasti\%C3\%A1n Soler Tomo I 
Copyright (c) 2021 Osvaldo P. Brito Febles y Byron Ramiro Alcocer Castillo

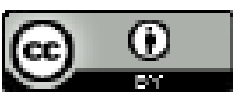

Este texto está protegido bajo una licencia internacional Creative Commons 4.0.

Usted es libre para Compartir-copiar y redistribuir el material en cualquier medio o formato

- y Adaptar el documento - remezclar, transformar y crear a partir del material-para cualquier propósito, incluso para fines comerciales, siempre que cumpla las condiciones de Atribución. Usted debe dar crédito a la obra original de manera adecuada, proporcionar un enlace a la licencia, e indicar si se han realizado cambios. Puede hacerlo en cualquier forma razonable, pero no de forma tal que sugiera que tiene el apoyo del licenciante o lo recibe por el uso que hace de la obra.

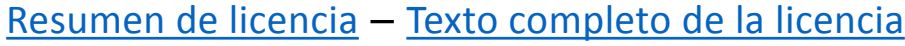

